\title{
Role of hypoxia-inducible- $1 \alpha$ in hepatocellular carcinoma cells using a Tet-on inducible system to regulate its expression in vitro
}

\author{
ZONGQUAN XU, ENYU LIU, CHENG PENG, YUNGUANG LI, ZHAOBIN HE, CHUANZONG ZHAO and JUN NIU
}

Department of Hepatobiliary Surgery, Qilu Hospital, Shandong University, Jinan 250012, P.R. China

Received August 10, 2011; Accepted October 6, 2011

DOI: $10.3892 /$ or.2011.1533

\begin{abstract}
Hypoxia-inducible-1 $\alpha$ (HIF-1 $\alpha$ ) expression was intimately correlated with apoptosis and proliferation of cancer cells. However, conclusions of different studies on the effects of HIF-1 $\alpha$ expression on cell apoptosis and cell proliferation of hepatoma cells remain controversial. In view of the current status, we reassess its roles and possible mechanism in hepatoma cells. In order to acquire more convincing and reliable results, we used a Tet-on system to stably and effectively regulate HIF-1 $\alpha$ expression in the HepG 2 cells in vitro. In our study we not only confirmed some common conclusions of previous studies, but also acquired some different and significant results that HIF-1 $\alpha$ facilitates cell proliferation and cell cycle through influencing the expression of cyclin A and cyclin D, and suppresses cell apoptosis through inducing the expression of survivin and $\mathrm{Bcl}-2$. These results further enrich our knowledge on the role of HIF-1 $\alpha$ expression on cell apoptosis and cell proliferation of hepatoma cells.
\end{abstract}

\section{Introduction}

Primary hepatocellular carcinoma is one of the most frequent tumors in the world with the characteristics of high malignancy, easily recurring within the liver and distant metastasis. The malignant biological behavior of hepatocellular cells are believed to be closely correlated with overexpression of hypoxia-inducible-1 $\alpha$ (HIF-1 $\alpha)$.

Hypoxia-inducible factor-1 (HIF-1) is a kind of DNA combining activating transcription factor, which can regulate gene expression under hypoxia conditions. HIF-1 consists of oxygen regulating subunit HIF- $1 \alpha$ and a structure subunit HIF-1 $\beta$. Both HIF- $1 \alpha$ and HIF-1 $\beta$ are the members of helix-loop-helix transcription factor family, and have the PerARNTSim (PAS) structural domain (1-4). HIF-1 $\beta$ is

Correspondence to: Dr Jun Niu, Department of Hepatobiliary Surgery, Qilu Hospital, Shandong University, Jinan 250012, P.R. China

E-mail: fz9809@yahoo.cn

Key words: hypoxia-inducible-1 $\alpha$, Tet-on inducible system, proliferation, apoptosis, hepatocellular carcinoma cells constitutively found in the nucleus, whereas stabilization of HIF-1 $\alpha$ and nuclear accumulation are induced by hypoxia. HIF-1 $\alpha$ is constitutively synthesized but sent to destruction by the ubiquitin proteasome pathway in normoxia (5-7). The downstream genes of HIF-1 $\alpha$ include cell proliferation and apoptosis gene, vascular endothelial growth factor (VEGF), erythropoietin gene, glucose transporter-1 and carbonic anhydrase (8-14). The activity of HIF-1 is mainly controlled by HIF-1 $\alpha$. Under hypoxic conditions, HIF-1 $\alpha$ accumulates quickly, translocates into the nucleus, and combines with hypoxia response element (HRE) of downstream target gene, forms a transcription initiation complex, switching on the downstream gene transcription.

Extensive experiments on the effects of HIF-1 $\alpha$ expression on tumor cell proliferation and apoptosis have been carried out. Unfortunately, they do not reach a consensus. On the issue of relationship between HIF-1 $\alpha$ and tumor cell proliferation, some researchers believed that high expression of HIF-1 $\alpha$ would impede tumor cell cycle and inhibit cell proliferation $(15,16)$, but others reached exactly the opposite results $(17,18)$. Whether HIF-1 $\alpha$ expression induce tumor cell apoptosis or not, different studies have varying conclusions. Ravi et al thought that HIF-1 $\alpha$ expression can promote tumor cell apoptosis (19), other studies demonstrated that HIF-1 $\alpha$ expression suppressed tumor cell apoptosis $(20,21)$, and some scholars showed that HIF-1 $\alpha$ expression did not influence tumor cell apoptosis at all $(22,23)$. Therefore, in order to investigate the role of HIF-1 $\alpha$ in hepatoma cells, we used a Tet-on inducible system $(24,25)$ to establish the HepG 2 cell line in which HIF-1 $\alpha$ expression could be stably expressed and regulated by adding doxycycline. Through reliably controlling and regulating the HIF- $1 \alpha$ expression, we could further indentify the effects of HIF-1 $\alpha$ expression on cell apoptosis and cell proliferation of hepatoma cells in vitro, and further explore the possible mechanism of its effect on cell apoptosis and cell proliferation. Our results will enrich our knowledge on the role and possible mechanism of HIF-1 $\alpha$ expression on hepatoma cell proliferation and apoptosis, and provide theory and experimental basis for molecular targeting therapy to HIF-1 $\alpha$.

\section{Materials and methods}

Chemicals and reagents. DMEM, fetal calf serum, pTet-On vector, PTRE2hyg vector, PTRE-luc vector were all obtained from BD Biosciences Clontech. Hygromycin, 
G418, and Lipofectamine 2000 were purchased from Invitrogen (Karlsruhe, Germany). RevertAid ${ }^{\mathrm{TM}}$ First Strand cDNA Synthesis kit, PfuUltra II fusion HS DNA polymerase were acquired from Fermentas (Shenzhen, China). Plasmid Maxi Preparation kit, TRIzol reagents, Restrict enzyme $B a m \mathrm{HI}, E c o \mathrm{RV}$, T4 ligation enzyme and random primer were all purchased from Gibco BRL, USA. Reagents for SDS-polyacrylamide gel electrophoresis (SDS-PAGE) and molecular weight markers were obtained from Bio-Rad Laboratories (Hercules, CA, USA). Cell Apoptosis Assay kit and Casepase-3 Assay kit was from Keygentec (Nanjing, China). Antibodies against HIF-1 $\alpha$, cyclin A, cyclin D, cyclin E were purchased from Santa Cruz Biotechnology (Santa Cruz, CA, USA). HepG2 and DH5 $\alpha$ were prepared from the experimental center of Hepatic Surgery Affiliated Tongji Hospital, Tongji Medical College of HuaZhong University of Science and Technology.

Establishment of the HepG2/HIF-1 $\alpha$ cell line in which HIF-1 $\alpha$ expression level is regulated by Tet-on gene expression. After RNA extraction from hypoxic HepG2 cells, cDNA was synthesized with reverse transcriptase as described in the introduction of cDNA Synthesis kit. For amplification of human HIF-1 $\alpha$, the following primers were used: HIF-1 $\alpha$ sense primer: 5'-ACCCTCTTCGTCGCTTCGGCCAGTGTG-3', HIF- $1 \alpha$ antisense primer: 5'-GTAATGAGCCACCAGTG TCAAAAAAAAGGAATGAA-3'; nested HIF- $1 \alpha$ sense primer: 5'-GTTTGGATCCAGCTTGCTCATGAGTTGC CACTTCCACATAATG-3', nested HIF-1 $\alpha$ antisense primer: 5'-CTGGATATCGTAATGAGCCACCAGTGTCCAAAAAA AGGAATGAA-3'. The nested HIF-1 $\alpha$ product was digested with BamHI and EcoRV and ligated into the BamHI and EcoRV linearized target vector pTRE2hyg so that we acquired pTRE-HIF-1 $\alpha$ containing the full length human HIF- $1 \alpha$. Positive clones were confirmed by restriction analysis as well as sequencing of the insert.

The expression plasmid pTet-on was transfected into HepG2 cells by lipofectamine 2000 . The stably transfected positive clones were screened with G 418 and subcultured. Through one by one by transient transfection of plasmid pTRE-luc into the stably transfected cells, we detected the expression level of luciferase induced by doxycycline at a concentration of $1 \mu \mathrm{g} /$ $\mathrm{ml}$ to screened efficiently and stably transfected cells (HepG2/ Tet-on cells). After successfully acquiring a pTet-on transfected human hepatoma HepG2 cell line (HepG2/Tet-on) regulated by doxycycline, the pTRE-HIF- $1 \alpha$ vector was transfected into HepG2/Tet-on cells by lipofectamine 2000. After $24 \mathrm{~h}$ of transfection, cells were selected for a double expression of the Tet regulator element as well as the expression of plasmid containing human HIF-1 $\alpha$ with G418 and hygromycin B. By adding doxycycline at a concentration of $1 \mu \mathrm{g} / \mathrm{ml}$, the Tet-On system was activated, and HIF-1 $\alpha$ was overexpressed in the cells under nomoxic conditions. The expression of HIF-1 $\alpha$ RNA and protein was detected to indentify the HepG2/ HIF-1a cells in which HIF-1 $\alpha$ was stably expressed and regulated by Tet-on inducible system.

Cell culture of the HepG2/HIF-1 $\alpha$ cells. The HepG2/ HIF-1 $\alpha$ cells were maintained as monolayers in standard medium comprising Dulbecco's modified Eagle's medium (DMEM:
$4.5 \mathrm{~g} / \mathrm{l}$ of glucose) containing $10 \%$ heat-inactivated fetal calf serum and supplemented with $20 \mathrm{mM}$ HEPES, $100 \mu \mathrm{g} / \mathrm{ml}$ penicillin and $100 \mu \mathrm{g} / \mathrm{ml}$ streptomycin (Merck, Germany). The cells were incubated in $37^{\circ} \mathrm{C}, 5 \% \mathrm{CO}_{2}$, and saturated humidity, and at the same time cells were respectively exposed at a concentration of doxycycline of $0,0.02,0.2,1,2$ and $5 \mu \mathrm{g} / \mathrm{ml}$ for $48 \mathrm{~h}$.

Cell proliferation assay. Cell viability was determined by measuring cellular metabolism using the 3-(4, 5-dimethylthiazol-2-yl)-2, 5-diphenyltetrazolium bromide (MTT) assay. In brief, cells were plated at 5,000 cells/well in 96-well tissue culture plates. After treatment at the different concentration of doxycycline, MTT was added to each well at a final concentration of $5 \mathrm{mg} / \mathrm{ml}$, and the cells were incubated for $4 \mathrm{~h}$ at $37^{\circ} \mathrm{C}$. The medium was then removed, and the cells were dissolved with dimethyl sulfoxide (DMSO) (Sigma, USA). Absorbance was measured at $570 \mathrm{~nm}$ (referenced to $650 \mathrm{~nm}$ ) in a Microplate Reader (Bio-Tech Instruments, USA).

Cell cycle assay. After the HepG2/ HIF-1 $\alpha$ cells were treated at the different concentration of doxycycline for $48 \mathrm{~h}$, each group of cells was washed with PBS, trypsinized and fixed with 70\% ethanol at $-20^{\circ} \mathrm{C}$ for $30 \mathrm{~min}$. Fixed cells were incubated with Propidium Iodide (PI) solution for $15 \mathrm{~min}$ and $10^{6}$ cells of each culture bottle was harvested and analyzed with FACScan Becton Dickenson flow cytometer, USA.

Western blotting. The HepG2/ HIF-1 $\alpha$ cells were treated at the different concentration of doxycycline for $48 \mathrm{~h}$. Both adherent and floating cells were collected and frozen at $-80^{\circ} \mathrm{C}$. To detect the levels of cyclin D1, cyclin E and cyclin A, TCM from those cells was concentrated 50-fold; the protein content was measured using the BCA protein assay reagent and $10 \mu \mathrm{g}$ was electrophoresed on a $12.5 \%$ SDS-PAGE gel under nonreducing conditions. Prior to loading the sample on the gel, the protein loads were equalized, and the electrophoresed proteins were transferred to nitrocellulose membranes. An equivalent protein loading for each lane was reconfirmed by staining the nitrocellulose membrane with Ponceau using the $36-\mathrm{kDa}$ GAPDH band present in the ITS supplement as a reference marker. Membranes were then probed with primary polyclonal antibody against cyclin D1, E and A, followed by peroxidaselabeled secondary antibodies. Western blots were visualized using the enhanced chemiluminescence detection system according to the manufacturer's instructions.

Detection of apoptosis by Annexin V/propidium iodide flow cytometric analysis. The HepG2/HIF- $\alpha$ cells were treated at the different concentration of doxycycline for $48 \mathrm{~h}$, where at the same time each group of cells was incubated at a concentration of ADM $(0.1 \mathrm{mg} / \mathrm{ml})$. Then each group of cells was detached by $0.25 \%$ trypsin and washed twice with cold phosphate-buffered saline. Cells were stained with Annexin V-FITC according to the manufacturer's protocol. Cells were analyzed on a FACS Calibur flow cytometer, and data analysis was performed with CellQuest software (Becton Dickinson). Since necrotic cells also exhibited phosphatidyl serine due to the loss of membrane integrity, DNA staining with propidium iodide, added to the Annexin V-FITC solu- 

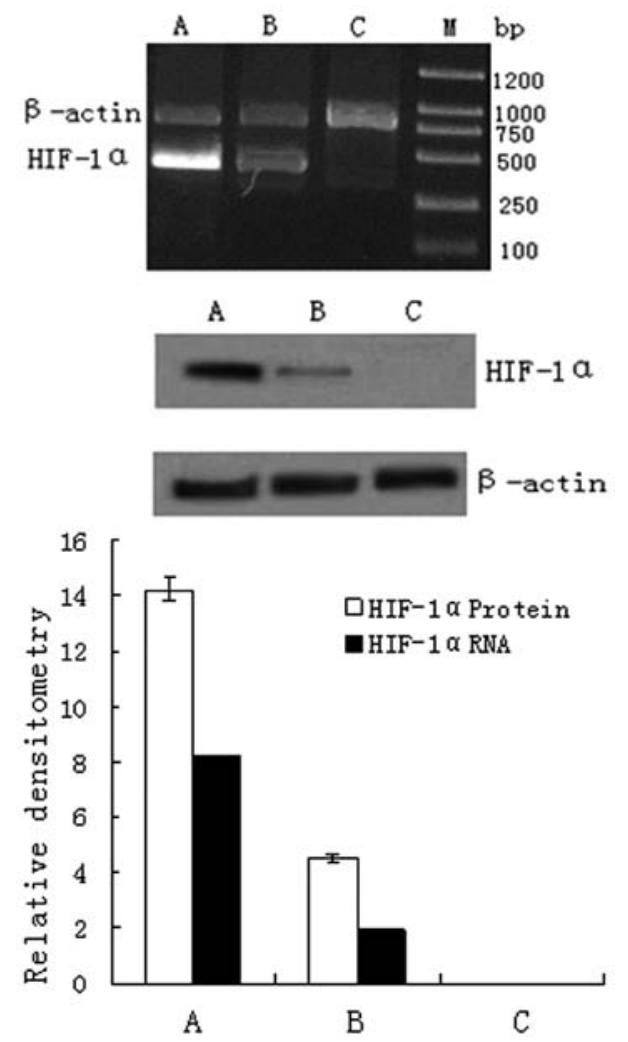

Figure 1. Expression of HIF-1 $\alpha$ RNA and protein in the HepG2/HIF-1 $\alpha$ cells. Lane A, doxycycline: $1 \mu \mathrm{g} / \mathrm{ml}$; lane B, doxycycline: $0 \mu \mathrm{g} / \mathrm{ml}$; lane $\mathrm{C}$, HepG2; lane M, Marker.

tion, was used to distinguish necrotic cells from the Annexin $\mathrm{V}$ positive stained cell clusters.

Assay of caspase activity. Each group of cultured cells were lysed with a lysis buffer containing $50 \mathrm{mM}$ Tris (pH 7.4), $1 \mathrm{mM}$ EDTA, $10 \mathrm{mM}$ EGTA, and $10 \mu \mathrm{M}$ digitonin. The soluble fraction of the cell lysate was then assayed for caspase-3 activity using Ac-DEVD-pNA, a colorimetric substrate for caspase-3, according to the manufacturer's instructions.

Semi-quantitative reverse transcription-PCR analysis. After the HepG2/ HIF-1 $\alpha$ cells were treated at the different concentration of doxycycline for $48 \mathrm{~h}$, we converted $1 \mu \mathrm{g}$ of total RNA extracted from each group of cultured cells to cDNA. The PCR regimen for survivin, $\mathrm{Bcl}-2$ and $\beta$-actin involved an initial denaturation step of $94^{\circ} \mathrm{C}$ for $30 \mathrm{sec}$, followed by 30 cycles at $94^{\circ} \mathrm{C}$ for $30 \mathrm{sec}, 54^{\circ} \mathrm{C}$ for $30 \mathrm{sec}$, and $72^{\circ} \mathrm{C}$ for $60 \mathrm{sec}$ on a GeneAmp PCR system 9700 (Perkin-Elmer). The synthesized cDNAs were amplified using specific sets of primers for survivin (sense: 5'-GGACCACCGCATCTCTACAT-3', antisense: 5'-GCACTTTCTTCGCAGTTTCC-3'), Bcl-2 (sense: 5'-CTGTACGGCCCCAGCATGCG-3', antisense: 5'-GCTTTGTTTCATGGTACATC-3') and $\beta$-actin (sense: 5'-CTGTTCCAGCCTTCCTTC-3', antisense: 5'-TCCTGC TTGCTAATCCAC-3').

Statistical analysis. Data are presented as the mean \pm SD. Statistical analysis was carried out using one-way ANOVA. Significance was set at $\mathrm{P}<0.05$.

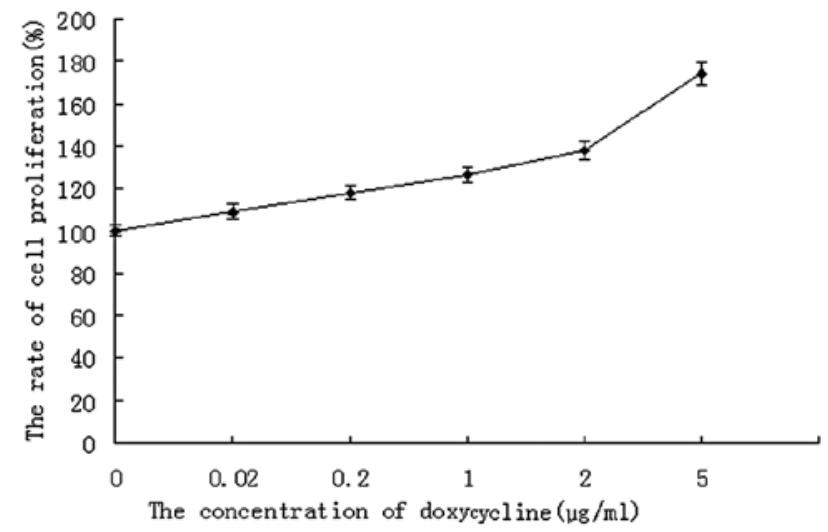

Figure 2. Effects of HIF-1 $\alpha$ on the HepG2 cell proliferation under different concentrations of doxycycline.

\section{Results}

Successful acquiring of the HepG2/HIF-1a cells where HIF-1a is stably expressed and regulated by Tet-on system. We successfully used a Tet-On system to regulate HIF-1 $\alpha$ expression in the HepG2 cells. After establishing a single positive Tet-On cell line by transfecting a vector (pTet-on) containing a reverse Tet repressor (rtTA), these cells were subjected to a second transfection introducing HIF-1 $\alpha$ within a response plasmid (pTRE-HIF-1 $\alpha$ ) containing a promoter being activated after binding of rtTA in the presence of doxycycline. The doublepositive cells were selected for expression of both plasmids. To confirm the activity of our inducible system, we detected the expression of HIF-1 $\alpha$ RNA and protein in the HepG2/HIF-1 $\alpha$ cells (Fig. 1). The outcome of detection showed that HIF-1 $\alpha$ can be stably expressed and regulated in the HepG 2 cells by Tet-On system.

Increased effects of HIF-1 $\alpha$ on HepG2 cell proliferation by doxycycline treatment. The MTT assay showed that, with the increasing of the concentration of doxycycline $(0,0.02$, $0.2,1,2$ and $5 \mu \mathrm{g} / \mathrm{ml}$ ), up-regulation of HIF- $1 \alpha$ expression could promote the HepG2 cell proliferation activities, and the number of viable cells increased in a dose-dependent manner (Fig. 2).

Cell cycle assay by flow cytometry. After being incubated under the different concentrations of doxycycline for $48 \mathrm{~h}$, The cell index of $S$ and $\mathrm{G}_{2} / \mathrm{M}$ phase was significantly higher and that of $G_{0} / G_{1}$ phase reduced with the increasing concentrations of doxycycline. This outcome demonstrated that HIF-1 $\alpha$ expression facilitated the HepG2 cell cycle (Table I).

Protein expression of cyclin D1, E and A. After being incubated under the different concentrations of doxycycline for $48 \mathrm{~h}$, the protein expression of cyclin D1 and A was increased with the increasing concentrations of doxycycline $(\mathrm{P}<0.01)$, cyclin $\mathrm{E}$ had no change $(\mathrm{P}>0.05)$ (Fig. 3). Western Blot detection showed HIF-1 $\alpha$ expression up-regulated the expression of cyclin D1 and $\mathrm{A}$.

Apoptosis examined by flow cytometry. After being incubated under the different concentrations of doxycycline for $48 \mathrm{~h}$, 
Table I. Effect of HIF-1 $\alpha$ on HepG2 cell cycle.

\begin{tabular}{lcccr}
\hline & & \multicolumn{3}{c}{ Distribution of cell cycle (\%) } \\
\cline { 3 - 4 } Group (doxycycline $\mu \mathrm{g} / \mathrm{ml})$ & $\mathrm{n}$ & $\mathrm{G}_{0} / \mathrm{G}_{1}$ & $\mathrm{~S}$ & $\mathrm{G}_{2} / \mathrm{M}$ \\
\hline 0 & 10 & $68.63 \pm 1.31$ & $21.56 \pm 1.34$ & $9.27 \pm 0.03$ \\
0.02 & 10 & $60.03 \pm 0.93$ & $25.25 \pm 1.62$ & $13.11 \pm 0.03$ \\
0.2 & 10 & $50.87 \pm 0.68$ & $31.07 \pm 1.34$ & $17.56 \pm 0.47$ \\
1 & 10 & $44.77 \pm 0.84$ & $35.55 \pm 0.71$ & $20.21 \pm 0.05$ \\
2 & 10 & $37.44 \pm 0.64$ & $38.63 \pm 0.91$ & $23.12 \pm 0.08$ \\
5 & 10 & $31.58 \pm 0.94$ & $41.68 \pm 1.55$ & $27.26 \pm 0.32$ \\
\hline
\end{tabular}

$\mathrm{F} \mathrm{G}_{0} / \mathrm{G}_{1}=108.535 \mathrm{P}<0.001, \mathrm{Fs}=73.044 \mathrm{P}<0.001, \mathrm{FG}_{2} / \mathrm{M}=59.353 \mathrm{P}<0.001$.

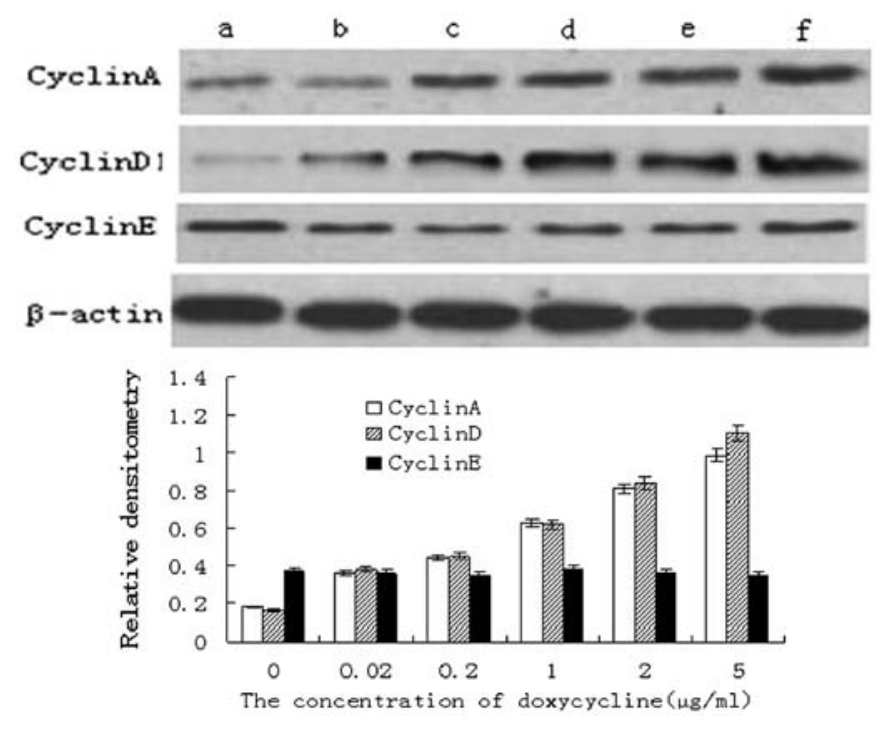

Figure 3. Effect of the different HIF-1 $\alpha$ expression level on the protein expression of cyclin D1, E and A. The concentration of a-f group is respectively $0,0.02,0.2,1,2$ and $5 \mu \mathrm{g} / \mathrm{ml}$.

HIF-1 $\alpha$ gene inhibited HepG2 cell apoptosis. The apoptosis rates were $59.6,50.9,38.1,30.5,23.9,18.3 \%$ respectively when the concentrations of doxycycline were $0,0.02,0.2,1,2$ and $5 \mu \mathrm{g} / \mathrm{ml}(\mathrm{p}<0.01)$ (Fig. 4).

Reduced caspase-3 activity. After being incubated under the different concentrations of doxycycline for $48 \mathrm{~h}$, the caspase- 3 activity was significantly reduced with the increasing concentration of doxycycline. The relative activity of caspase- 3 of different groups of cells $(0.02,0.2,1,2$ and $5 \mu \mathrm{g} / \mathrm{ml})$ to the control groups $(0 \mu \mathrm{g} / \mathrm{ml})$ was, respectively, $2.3,5.5,8.7,12.6$, 18.8 times (Fig. 5). Assay of caspase activity suggested that HIF-1 $\alpha$ inhibited casepase-3 activity.

RNA expression of survivin and Bcl-2. After being incubated under the different concentrations of doxycycline for $48 \mathrm{~h}$, the intensity of survivin expression for each group of cultured cells was, respectively, $0.46 \pm 0.02,0.63 \pm 0.02,0.82 \pm 0.01$, $1.09 \pm 0.04,1.50 \pm 0.07,1.90 \pm 0.05$ and that of Bcl-2 expression was, respectively, $0.20 \pm 0.02,0.30 \pm 0.02,0.49 \pm 0.03,0.61 \pm 0.02$, $1.03 \pm 0.03,1.24 \pm 0.07$ (Fig. 6). The semi-quantitative RT-PCR

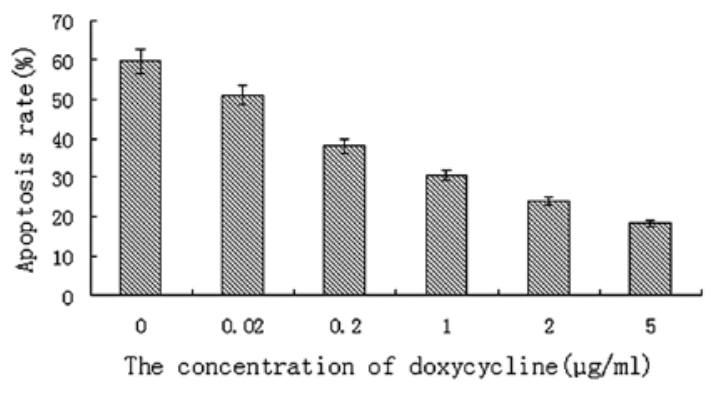

Figure 4. Apoptotic rate of HepG2 cells under the different HIF-1o expression level, the concentration of groups, respectively, from left to right: $0,0.02,0.2,1,2$, and $5 \mu \mathrm{g} / \mathrm{ml}$.

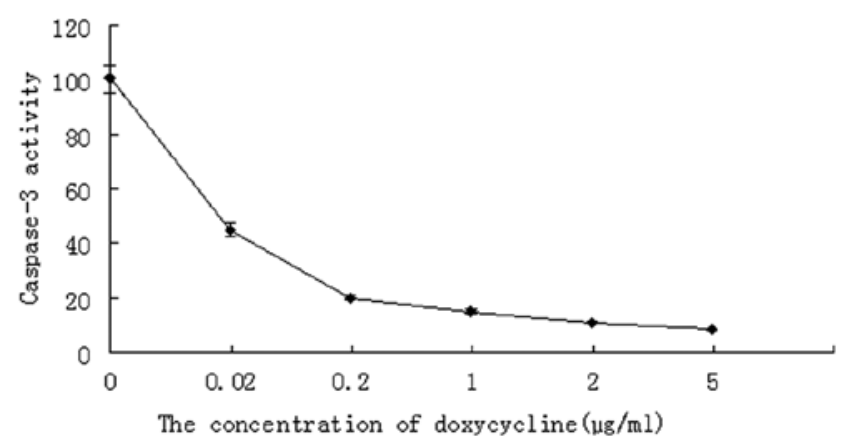

Figure 5. Effect of the different HIF-1 $\alpha$ expression level on caspase-3 activity.

assay shows that the mRNA expression intensity of survivin and Bcl-2 increased with HIF-1 $\alpha$ expression increase.

\section{Discussion}

HIF-1 $\alpha$ plays an important role in regulating hepatoma cell proliferation and apoptosis. Unfortunately, there have been controversies about the results of HIF-1 $\alpha$ in hepatoma cells. Therefore, it is very important to validate the role and mechanism that HIF-1 $\alpha$ plays in hepatoma cells. The aim of the current study was to reappraise the role and feasible mechanism of HIF-1 $\alpha$ in hepatoma cells under normoxia condition. We believe this investigation can add further knowledge to clarify the role of HIF-1 $\alpha$. 

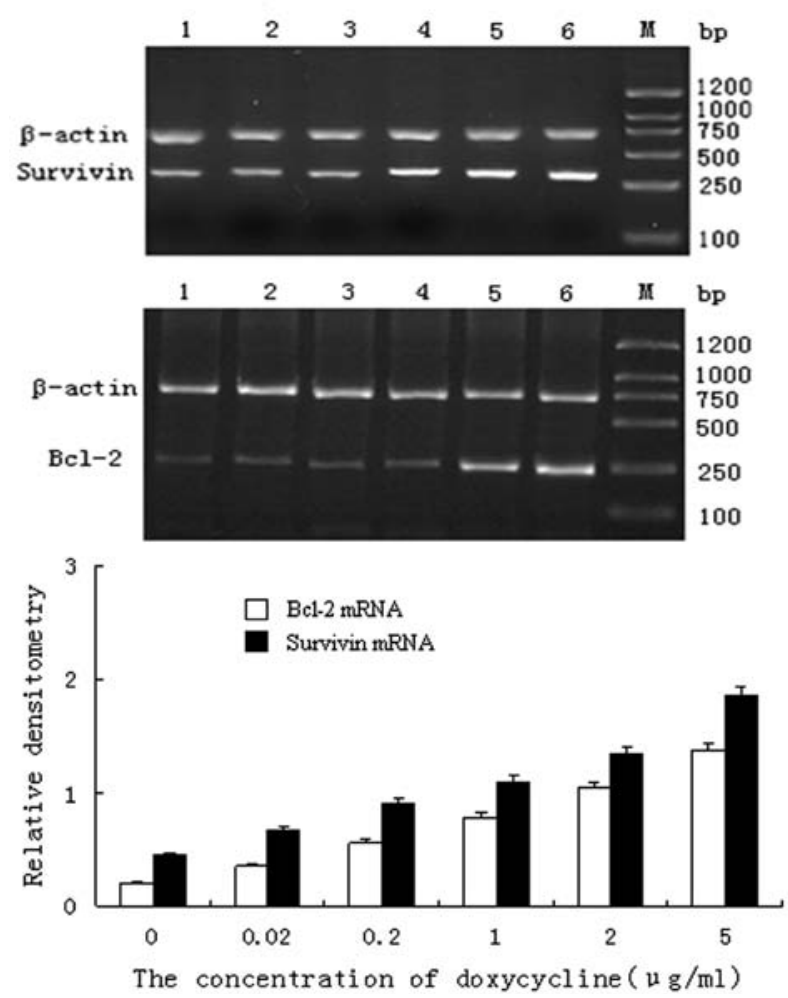

Figure 6. Effect of the different HIF-1 $\alpha$ expression levels on survivin and Bcl-2. Concentration of groups, respectively, from left to right: 0, 0.02, 0.2, 1, 2 and $5 \mu \mathrm{g} / \mathrm{ml}$. M, marker; survivin, $349 \mathrm{bp}$; Bcl-2, $231 \mathrm{bp}$.

Our study results were consistent with some other experimental conclusions $(17,18,20,21)$. Our study has proven that HIF-1 $\alpha$ participated in cell proliferation and cell apoptosis in Hepatocellular carcinoma, and it inhibited cell apoptosis, promoted cell proliferation and accelerated the cell cycle in vitro. We believe that HIF-1 $\alpha$ facilitates cell proliferation and accelerates the cell cycle influencing the expression of cyclin A and cyclin D, and suppresses cell apoptosis through inducing the expression of survivin and Bcl-2 and inhibits caspase-3 activity.

Our experimental results are contradictory with some other investigations $(15,16,22,23)$, one possible reason is that we deployed a new experimental platform in which HIF-1 $\alpha$ can be stably expressed. In the current study, we used a Tet-on inducible system to regulate HIF-1 $\alpha$ expression in vitro. This experiment is easy to manipulate, and HIF-1 $\alpha$ expression under normoxia condition is stable and dose-dependent on doxycycline, so the experimental results were more reliable.

Cyclin D1 is an important regulatory factor controlling the restriction point of cell cycle $G_{1}$. The augmentation of cyclin D1 expression can shorten the process of cell cycle or speed up the cell cycle $G_{1}$. In contrast, the depressed expression of cyclin D1 can induce the cell cycle arrest. Cyclin $\mathrm{A}$ is a positive regulatory factor during the process of cell proliferation, and participates in the DNA synthesis and replication, so it is an essential factor for cell cycle $\mathrm{S}$ and $\mathrm{G}_{2} / \mathrm{M}$. The increased expression of cyclin $\mathrm{A}$ can induce the activity of cell proliferation. Studies demonstrated that cyclin D1 was a hypoxia response gene, and the combination of cyclin D1 with hypoxia reponse element can promote the expression of cyclin D1 under hypoxia condition (26). It has been shown that high expression of HIF-1 $\alpha$ advanced tumor cell proliferation and correlated with cyclin A and Ki-67 $(27,28)$. These experimental results were consistent with our conclusions. Therefore, controlling and regulating cyclin A and cyclin D expression may be an important pathway of HIF-1 $\alpha$ influencing cell proliferation and cell cycle.

Survivin is a member of the inhibitor of apoptosis protein (IAP) family, and expressed in almost all the human tumors. Bcl-2 can inhibit cell apoptosis resulting from various reasons. Bcl-2 blocks the activation of caspase upstream through interfering with the release of cytochrome-c from mitochondrion, but survivin blocks cell apoptosis mainly via inhibiting the activity of caspase-3, the downstream effector molecule of the apoptosis signal transduction pathway (29). Although the mechanism of Bcl-2 and survivin was different, they both acted as resistance to cell apoptosis. Possible reason is that Bcl-2 and surviving gene are regulated by promoter molecule including non-tumor-associated antigen and affluent guanine and cytosine, and obviously expressed in the athletic cells. This phenomenon indicated that both may be controlled and regulated by a common transcriptional activation mechanism and facilitate cell proliferation and the development of tumor cells. In our experiment the assay of caspase activity found that HIF-1 $\alpha$ inhibited caspase- 3 activity, so we detected Bcl-2 and survivin expression in order to explore possible factors influencing casepase-3 activity. Our studies found that the mRNA expression of survivin and $\mathrm{Bcl}-2$ increased according to HIF-1 $\alpha$ expression increase. In our study HIF-1 $\alpha$ suppressed hepatocellular cell apoptosis by regulating survivin and Bcl-2 expression.

Taken together, we deployed a Tet inducible system to stably and reliably regulate HIF- $1 \alpha$ expression in the HepG2 cell lines in vitro. Through this system, we clarified the effect of HIF-1 $\alpha$ on hepatoma cells and further explore the possible mechanism. Our experimental conclusions further enriched our knowledge on the mechanism of action of HIF-1 $\alpha$ expression on cell apoptosis and cell proliferation of hepatoma cells.

\section{Acknowledgements}

This study was supported by the National Natural Sciences Foundation Research Grant of China (No. 30570833), and the Shandong Provincial Natural Sciences Foundation Research Grant (No. Y2005C42).

\section{References}

1. Wang GL, Jiang BH, Rue EA and Semenza GL: Hypoxiainducible factor 1 is basic-helix-loop-helix-PAS heterodimer regulated by cellular $\mathrm{O}_{2}$ tension. Proc Natl Acad Sci USA 92: 5510-5514, 1995.

2. Ema M, Taya S, Yokotani N, Sogawa K, Matsuda Y and FujiiKuriyama Y: A novel bHLH-PAS factor with close sequence similarity to hypoxia-inducible factor $1 \alpha$ regulates the VEGF expression and is potentially involved in lung and vascular development. Proc Natl Acad Sci USA 94: 4273-4278, 1997.

3. Tian H, McKnight SL and Russell DW: Endothelial PAS domain protein 1 (EPAS1), a transcription factor selectively expressed in endothelial cells. Genes Dev 11: 72-82, 1997.

4. Gu YZ, Moran SM, Hogenesch JB, Wartman L and Bradfield CA: Molecular characterization and chromosomal localization of a third alpha-class hypoxia inducible factor subunit, HIF3alpha. Gene Expr 7: 205-213, 1998. 
5. Salceda S and Caro J: Hypoxia-inducible factor $1 \alpha$ (HIF-1 $\alpha)$ protein is rapidly degraded by the ubiquitin-proteasome system under normoxic conditions. Its stabilization by hypoxia depends on redox-induced changes. J Biol Chem 272: 22642-22647, 1997.

6. Huang LE, Gu J, Schau M and Bunn HF: Regulation of hypoxiainducible factor $1 \alpha$ is mediated by an $\mathrm{O}_{2}$-dependent degradation domain via the ubiquitin-proteasome pathway. Proc Natl Acad Sci USA 95: 7987-7992, 1998

7. Kallio PJ, Wilson WJ, O'Brien S, Makino Y and Poellinger L: Regulation of the hypoxia-inducible transcription factor $1 \alpha$ by the ubiquitin-proteasome pathway. J Biol Chem 274: 6519-6525, 1999.

8. Semenza GL: HIF-1 and human disease: one highly involved factor. Genes Dev 14: 1983-1991, 2000

9. Semenza GL: HIF-1: using two hands to flip the angiogenic switch. Cancer Metastasis Rev 19: 59-65, 2000.

10. Wang GL and Semenza GL: General involvement of hypoxiainducible factor 1 in transcriptional response to hypoxia. Proc Natl Acad Sci USA 90: 4304-4308, 1993.

11. Grosfeld A, Andre J, Hauguel-De Mouzon S, Berra E, Pouyssegur J and Guerre-Millo M: Hypoxia-inducible factor 1 transactivates the human leptin gene promoter. J Biol Chem 277: 42953-42957, 2002.

12. Meissner U, Ostreicher I, Allabauer I, Rascher W and Dotsch J: Synergistic effects of hypoxia and insulin are regulated by different transcriptional elements of the human leptin promoter Biochem Biophys Res Commun 303: 707-712, 2003.

13. Wenger RH: Cellular adaptation to hypoxia: $\mathrm{O}_{2}$-sensing protein hydroxylases, hypoxia-inducible transcription factors, and $\mathrm{O}_{2}$-regulated gene expression. FASEB J 16: 1151-1162, 2002.

14. Bracken CP, Whitelaw ML and Peet DJ: The hypoxia-inducible factors: key transcriptional regulators of hypoxic responses. Cell Mol Life Sci 60: 1376-1393, 2003.

15. Iida T, Mine S, Fujimoto H, et al: Hypoxia-inducible factor- $1 \alpha$ induces cell cycle arrest of endothelial cells. Genes Cells 7 143-149, 2002.

16. Koshiji M, Kageyama Y, Pete EA, Horikawa I, Barrett JC and Huang LE: HIF-1 $\alpha$ induces cell cycle arrest by functionally counteracting Myc. EMBO J 23: 1949-1956, 2004.

17. Hopfl G, Weager RH,Ziegler U, et al: Rescue of hypoxia-inducible factor-1 alpha deficient tumor growth by wild-type cells is independent of vascular endothelial growth factor. Cancer Res 62: 2962-2970, 2002.
18. Carmeliet P, Dor Y, Herbert JM, et al: Role of HIF-1alpha in hypoxia-mediated apoptosis, cell proliferation and tumour angiogenesis. Nature 394: 485-490, 1998.

19. Ravi R, Mookerjee B, Bhujwalla ZM, et al: Regulation of tumor angiogenesis by P53-induced degradation of hypoxia-inducible factor 1alpha. Genes Dev 14: 34-44, 2000.

20. Zhang Q, Zhang ZF, Rao JY, Sato JD, Brown J, Messadi DV and Le AD: Treatment with siRNA and antisense oligonucleotides targeted to HIF-1alpha induced apoptosis in human tongue squamous cell carcinomas. Int J Cancer 111: 849-857, 2004.

21. Greijer AE and Van der Wall E: The role of hypoxia inducible factor-1 (H IF-1) in hypoxia induced apoptosis. J Clin Pathol 57: 1009-1014, 2004.

22. Hall JL, Wang XH, Van Adamson, Zhao Y and Gibbons GH: Overexpression of Ref-1 inhibits hypoxia and tumor necrosis factor-induced endothelial cell apoptosis through nuclear factor kappab-independent and -dependent pathways. Circ Res 88: $1247-1253,2001$

23. Mizutani A, Furukawa T, Adachi Y, Ikehara S and Taketani S: A zinc-finger protein, PLAGL2, induces the expression of a proapoptotic protein Nip3, leading to cellular apoptosis. J Biol Chem 277: 15851-15858, 2002.

24. Gossen M, Freundlieb S, Bender G, Muller G, Hillen W and Bujard H: Transcriptional activation by tetracyclines in mammalian cells. Science 268: 1766-1769, 1995 .

25. Gossen $\mathrm{M}$ and Bujard $\mathrm{H}$ : Tight control of gene expression in mammalian cells by tetracycline responsive promoters. Proc Natl Acad Sci USA 89: 5547-5551, 1992.

26. Laurance ME, Starr DB, Michelatti EF, et al: Specific down regulation of an engineered human cyclinD1 promoter by a novel DNA-binding ligand in intact cells. Nucleic Acids Res 29: 652-666, 2001.

27. Bos R, van Diest PJ, van der Groep P, Shvarts A, Greijer AE and van der Wall E: Expression of hypoxia-inducible factor- $1 \alpha$ and cell cycle proteins in invasive breast cancer are estrogen receptor related. Breast Cancer Res 6: 450-459, 2004.

28. Zhong H, De Marzo AM, Laughner E, et al: Overexpression of hypoxia-inducible factor-1 in common human cancers and their metastases. Cancer Res 59: 5830-5835, 1999.

29. Shin S, Sung BJ, Cho YS, et al: An anti-apoptotic protein human survivin is a direct inhibitor of casepase- 3 and-7. Biochemistry 40: 1117-1123, 2001. 